\title{
Submergence Tolerance in Irrigated and Rainfed Lowland Rice Varieties: Agro-Morphological Basis for Rice Genetic Improvement in Southern Benin
}

\author{
Magloire Oteyami ${ }^{*}$, Espérance Codjia ${ }^{1}$, Clement Agbangla ${ }^{1}$, Leonard Ahoton ${ }^{1}$, Carline Santos ${ }^{1}$, \\ David Montcho' ${ }^{2}$ Antoine Missihoun ${ }^{1}$
}

${ }^{1}$ University of Abomey-Calavi, Abomey Calavi, Benin

${ }^{2}$ National University of Agriculture, Abomey Calavi, Benin

Email: *moteyami@yahoo.fr

How to cite this paper: Oteyami, M., Codjia, E., Agbangla, C., Ahoton, L., Santos, C., Montcho, D. and Missihoun, A. (2018) Submergence Tolerance in Irrigated and Rainfed Lowland Rice Varieties: Agro-Morphological Basis for Rice Genetic Improvement in Southern Benin. Open Access Library Journal, 5: e4304.

https://doi.org/10.4236/oalib.1104304

Received: January 3, 2018

Accepted: April 5, 2018

Published: April 8, 2018

Copyright $\odot 2018$ by authors and Open Access Library Inc.

This work is licensed under the Creative Commons Attribution International License (CC BY 4.0).

http://creativecommons.org/licenses/by/4.0/

\begin{abstract}
Objective: The study was carried out, on the rice perimeter of Southern Benin, to evaluate the response of irrigated and lowland rice varieties to the complete and partial submergence using agro-morphological traits. Method: Thus, 15 rice varieties were submerged in the field during 60 days according to split plot experimental design with two factors and three replications. Agro-morphological parameters such as plant height, number of tillers, the distance of internodes and the number of internodes were measured respectively at 13 days and 45 days. After harvest, some traits such as length, width and thickness of grains, panicle length, number of primary and secondary branches, the average number of empty grains and full grains per panicle and 1000 -grain weight were recorded. Results: Very highly significant $(P \leq 0.0001)$ differences were identified between agro morphological parameters according to the type of submergence while the factor type of immersion has significant influence on the number of internodes at 45 days after transplanting $(\mathrm{P} \leq$ 0.01). The submergence was not significant effect on tillering and length of internodes. Conclusion: The plant height, the weight of thousand grains and the average number of empty grains per panicle constitute key aspects and have been essential for evaluating tolerance to submergence in Benin.
\end{abstract}

\section{Subject Areas}

Agricultural Science, Plant Science

\section{Keywords}

Rice, Submergence, Tolerance, Benin 


\section{Introduction}

$90 \%$ of the rice-growing areas are submerged during cultivation of rice in Asia, compared with 40 percent in Latin America and Africa in the West [1]. Indeed, rice is grown in different ecologies from uplands to swampy areas [2]. However, when it is exposed to more than $25 \mathrm{~cm}$ of water or full immersion, the rice is severely damaged resulting in losses [3]. With the climate trend observed over the last thirty years [4], there will be an excessive rainfall, thus causing an increase in the negative effect of the floods on food production; a situation that could get worse for rice production. In addition, it is important to remember that climate variations affect rice production, and will continue to do so through irregular precipitation, more dry periods during the wet season, droughts and floods that penalize rice yields [5]. The yield of rice in terms of submergence is very low for most of the time below $1.5 \mathrm{t} /$ ha because producers continue to grow their traditional low-yield and susceptible to abiotic and biotic constraints; this is due to non-availability of rice varieties tolerant to flooding or submergence [6].

It's important to know that the years 2009 and 2010 were exceptional in rainy and raw years in the region, West African [7]. In the Oueme Valley rice six Commons were severely affected. It's the Cove towns, Zangnanado, of Ouinhi, of Bonou, of Adjohoun, of Dangbo [8]. Zagnanado and Ouinhi towns located at the entrance of the delta have been particularly affected more than the other four (04) towns. These communities have experienced overall $59 \mathrm{~km}$ of degraded slopes, 10,995 washed tons of crops of maize and Cowpea in stock, 8860 heads of cattle all missing species, 148 fish holes submerged in the period from July to October [8] these statistics show the extent of the problem of flooding and as a result the flooding of crops in South - Benin. In addition, water supply is sufficient during the rainy season in such a way that without artificial irrigation; agricultural production can take place throughout the year. Due to the strong population growth and the reduction of arable land, exploitation of the underground is so very important for the future of this region [9]. The additional production required to meet this demand will have to come largely from the gutter, although they represent only a small fraction (5\%) of the arable land in Africa from the West [10]. However, these rice ecologies are facing flooding, crops irrigated with water (rice to submergence) control, and/or to the flood, for crops without water (flooded rice or rice to submergence is not controlled) control. Lowlands's soils are subject to intense leaching, vertical or longitudinal, which is often initially under the surface horizon, of sands or clays white, totally leached horizons. This internal flow may also carry fine particulates, enriching in sands; the upstream areas or lateral of the lowlands. The homoscedasticity blocks the evolution of organic matter, which accumulates on the surface, in a more or less decomposed form. There are then soils organic, very acidic, with very low capacity of cationic Exchange. In mineral soils, organic matter rates are highly variable and can reach $8 \%$ to $10 \%$. However, far to be a sign of fertility, this accumulation of organic matter, high $\mathrm{C} / \mathrm{n}$, is actually a sign of the more or 
less complete blocking of biological life. The mineral wealth of the soils of lowland is often very low. Flooding creates in effect of anaerobic conditions, resulting in reduction reactions [11]. As a result, plants grown in frequently flooded areas are often reduced biological production [12]. This therefore translates into a decline in performance [13] and the death of submerged rice plants. The main constraint for plants, during the flood, is the lack of oxygen [14]. This decreases root respiration, inhibits the growth of the underground and aerial part and results in the senescence of the latter [15].

Although over three quarters of West Africa are located in semi-arid and arid climates, several areas are flooded during the winter period and are temporarily inaccessible and abandoned. These areas have a clayey or silty structure does not allow a quick interflow during heavy precipitation. The choice of species to grow on these soils is of considerable importance for the cultivation of rice in order to contribute to food security and sustainability of local resources of small producers of rice in West Africa.

The current study was conducted in the town of Cove (adjacent municipality of Zagnanando) specifically to Koussin-lele. Indeed, every year, an overflow of the river Zou observed on rice Koussin-lele perimeter; that creates a situation of total submergence or partial submergence of rice plants at any stage of their development.

\section{Study Area}

The area of study for this research is located in the district Cove of Benin between $2^{\circ} 58^{\prime}$ east longitude and $7^{\circ} 25^{\prime}$ north latitude It covers an area of $525 \mathrm{~km}^{2}$ and is remote to Cotonou Agreement of $150 \mathrm{~km}$ about by Bohicon. The soil types encountered in the study area are dominated by soils hydromorphic whose texture is clay-silty.

Figure 1 presents the heights of rainfall recorded in study area during the course of the year 2015 with a precision of the number of days of rain. This figure confirms that the period of July to October (period of implementation) is a

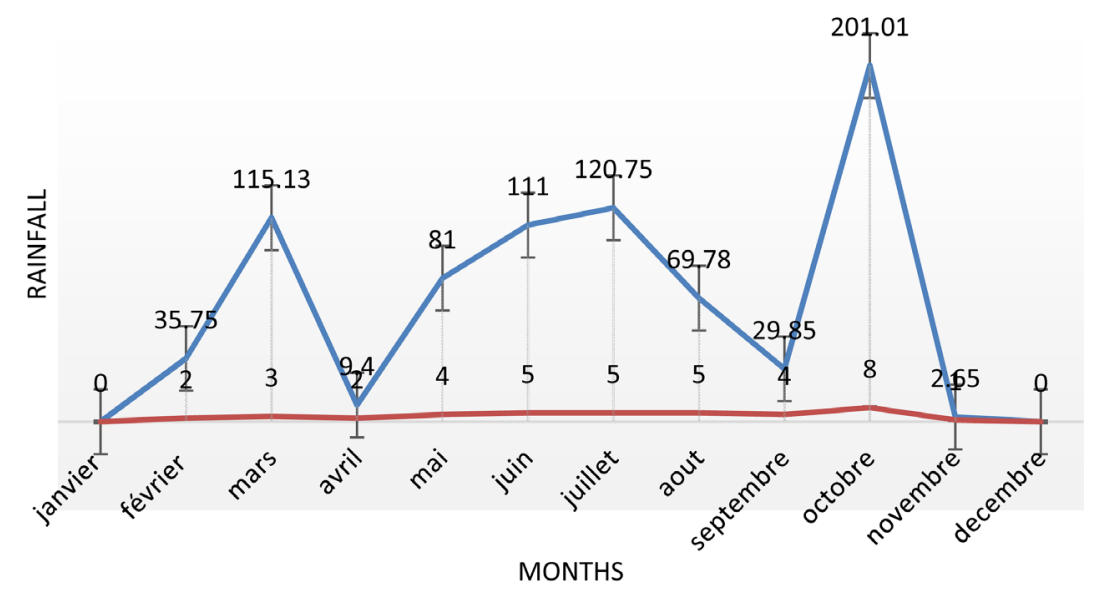

Figure 1. Heights of rainfall. 
period during which the maximum heights of rains have been recorded. It is important to note that the month of August usually marks the beginning of the period of flood during which the flood is observed on the Rice perimeter of Koussin-lele. Figure 1 show the heights of rainfall.

\section{Implementation of Study}

The test has been put in lowland perimeter of Koussin-lele. This test has need 15 varieties submitted in condition of submergence in a device of split-plot composed of three large plots. Has this effect, after a nursery in 17 days, the young seedlings were transplanted in lines by reason of a single plant per hill following the plan of randomization. For the experimentation, each variety has been installed on a plot of $1 \mathrm{~m}^{2}$ according to a clearance of $25 \mathrm{~cm}$ between seedlings and lines per plot. The plants of rice have stayed in the water during 60 days. The level of the water has been increased and adjusted for each type of treatment to a maximum height amounting to up to $100 \mathrm{~cm}$.

As regards fertilization, a manuring of funds to reason to $200 \mathrm{~kg} / \mathrm{ha} \mathrm{NPK}$ and $100 \mathrm{~kg} / \mathrm{ha}$ of urea which $50 \mathrm{~kg} / \mathrm{ha}$ and $50 \mathrm{~kg} / \mathrm{ha}$ to filling of the grain has been performed. Finally, for the management of weeds, manual weeding was performed three times before the stage of maturity of the grain more particularly in the block have not suffered flooding. An adjustment of the fluctuation of the blade of water in the racks is performed every three days by a contribution or withdrawal of water according to the case and the need in the various types of flooding (T0, T1 and T2).

\section{Methods}

In total, 15 varieties from two species of cultivated rice (O. glaberrima and $O$. sativa) as well as the varieties of intra and interspecific (NERICA-L and the ARICA, etc.) have formed the working collection. Table 1 demonstrates Genetic characteristics of plant material.

The experimental design used is a split plot. Three large plots were carried out each with three repetitions of 15 varieties and therefore 45 under plots by large parcel. The first large parcel is subjected to a treatment witness T0 without submergence, the second is subjected to a treatment T1 (partial submergence) and the third large parcel to the T2 (total submergence) treatment. Indeed, all three types of treatment are not in a large parcel. Thus, each large parcel in this case represents a type of treatment $\mathrm{T} 0, \mathrm{~T} 1$ or $\mathrm{T} 2$. Two factors have been so studied during the test. It's the type factor of submergence and the variety factor. 15 varieties were tested in different heights or blade of water (without submergence, partial submergence, and total submergence). Figure 2 shows the randomization plan adopted during the test.

Growth parameters measured include: the height, number of tillers, number of internodes, and length of internodes. These measures were made on 4 plants per plot of $1 \mathrm{~m}^{2}$. About measured performance metrics, its length, width and 
Table 1. Genetic characteristics of plant material.

\begin{tabular}{ccccc}
\hline Varieties & Pedigree & Parents & Status & Ecology \\
\hline ARICA1 & & - & Interspecific & Rainfed lowland \\
ARICA2 & WAB-2056-2-FKR-2-5-TGR1-B & - & Interspecific & Rainfed lowland \\
ARICA3 & WAB-2076-WAC-1-TGR1-B & - & Interspecific & Rainfed lowland \\
NERICAL-19 & WAS122-IDSA-1-WAS-6-1 & TOG5681/3*IR64 & Interspecific & Irrigated lowland \\
NERICAL-20 & WAS122-IDSA-1-WAS-1-WAS-B & TOG5683/3*IR864 & Interspecific & Irrigated lowland \\
NERICAL-41 & WAS 161-B-9-3 & TOG5681//4IR64 & Interspecific & Irrigated lowland \\
NERICAL56 & WAS 191-8-3 & IR64/TOG5681//4IR64 & Interspecific & Irrigated lowland \\
TOG5810 & - & - & O. glaberrima & lowland \\
TOG5674 & - & - & O. glaberrima & lowland \\
TOG6523 & - & - & O. glaberrima & lowland \\
IR841 & - & - & O. sativa & Irrigated lowland \\
BL19 & - & - & O. sativa & Irrigated lowland \\
BR11Sub1 & - & - & Interspecific & lowland \\
SWARNA Sub1 & - & - & Interspecific & Interspecific \\
CIHERANG Sub1 & - & & & lowland \\
\hline
\end{tabular}

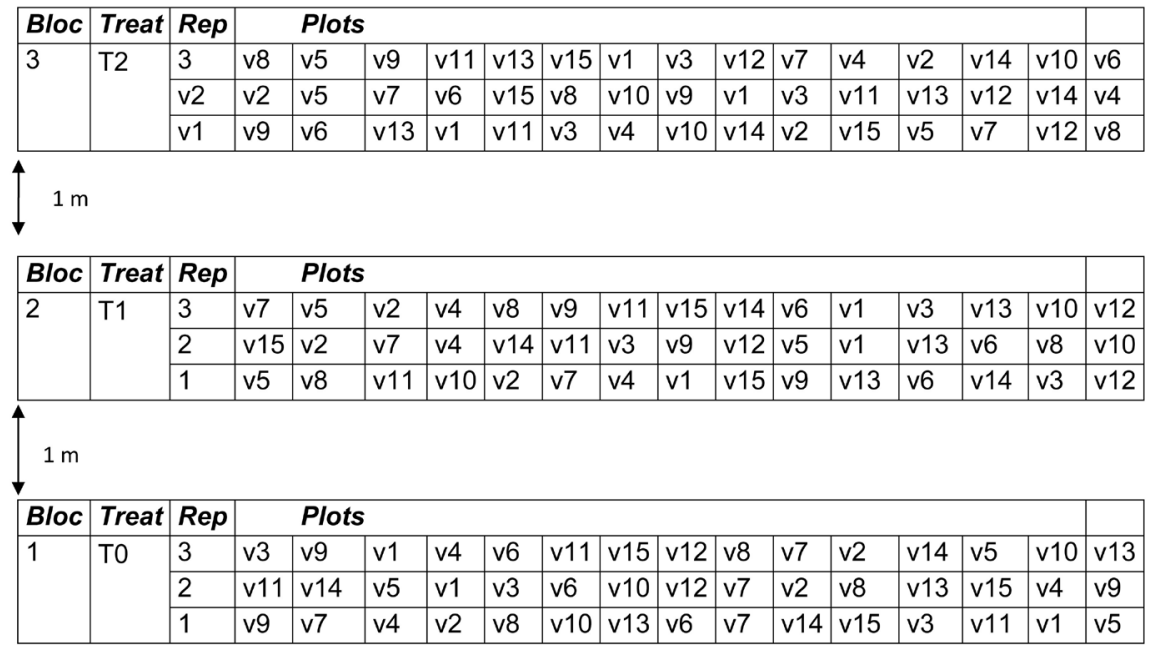

Figure 2. Randomization plan. Legend: v1 = ARICA2; v2 = TOG5674; v3 = ARICA3; v4 = ARICA1; v5 = TOG6523; v6 = TOG5810; v7 = NERICAL-19; v8 = NERICAL-20; v9 = BR11Sub1; v10 = CIHERANGSub1; v11 = SwarnaSub1; v12 = BL19; v13 = IR841; v14 = NERICAL-41; v15 = NERICAL-56.

thickness of the rice grains, panicle length, number of ramifications primary and secondary, the average number of empty grain and full grains per panicle and the weight of 1000 grains of rice. The data related to the performance were measured on 10 panicles selected by plot during the harvest. Two observations have been conducted during the test for plant growth parameters. The first 13 days after transplanting is three days of submergence and the second at 45 days after transplanting or 35 days of submersion of rice plants. 
The analysis of variance ANOVA was conducted for all the quantitative data taken to verify the significance of factors (variety and type of submergence) whereas the various parameters measured; allowing comparing the varieties in the three types of submergence. The software used in this analysis is the SAS version 9.2 software. This analysis has been done both for plant growth parameters of performance. The choice took into account not only parameters of growth and performance measured. It should be noted that this analysis was performed with the software R. version 3.2.2. The CPA also allowed to study the correlations between the variables of growth and performance variables on different axes that summarize more than half of the information.

\section{Results}

\subsection{Significance of the Factors on the Basis of Growth Traits}

The choice of variables of comparison depends on the influence of factors (in particular the interaction variety $\mathrm{x}$ submergence) on these variables. Thus, table of variance analysis shows that the type of submergence has an influence very highly significant $(P \leq 0.0001)$ on the height at 45 days after transplanting and the number of internodes at 30 days after transplanting; While the factor type of immersion has a significant influence on the number of internodes at 45 days after transplanting $(P \leq 0.01)$. It is worth noting that the submergence has no significant effect on tillering and length of internodes. In addition, the analysis of variance table reveals that the variety factor has an influence very highly significant $(P \leq 0.0001)$ on the height of the plants and on the number of internodes at 45 days after transplanting. In addition, parameters such as the tillering, the number of internodes and length of internodes are not influenced varieties. Interaction submergence and varieties has a very highly significant $(P \leq 0.0001)$ on the height of 45 days after transplanting plants and a significant effect on the number of internodes at 45 days after transplanting. The height and number of internodes at 45 days after transplanting have allowed to appreciate the effect of the submersion and at the same time the difference between varieties in submergence condition (Table 2). Table 2 demonstrates the significance of the variables.

\subsection{Comparison of the Height of the Varieties in the Three Types of Submergence}

\section{$\checkmark$ Without submergence}

The analysis of Figure 3 shows that TOG 5674 and ARICA1 and NERICAL-20 varieties have a height higher than those of other varieties in T0. These three varieties have respectively as average $83.55 \mathrm{~cm}$ and $82.83 \mathrm{~cm}, 78.66$ $\mathrm{cm}$. On the other hand, it is important to note that NERICA-L19 and SWARNA-Sub1 varieties are those that carry the lowest heights in normal condition without submersion. Means followed by the same letter are not significantly different. 
Table 2. Significance of the variables of plant growth.

\begin{tabular}{cccccccccc}
\hline \multirow{2}{*}{ SSV } & DDL & \multicolumn{7}{c}{ Values of F and probabilities } \\
\cline { 3 - 10 } & & H13JAR & H45JAR & T13JAR & T45JAR & NE30JAR & NE45JAR & DE30JAR & DE45JAR \\
\hline Submergence & 2 & $0.42 \mathrm{~ns}$ & $35.74^{* * *}$ & $0.84 \mathrm{~ns}$ & $0.97 \mathrm{~ns}$ & $18.79^{* * *}$ & $3.17^{*}$ & $1.50 \mathrm{~ns}$ & $0.98 \mathrm{~ns}$ \\
Varieties & 14 & $1.31 \mathrm{~ns}$ & $16.24^{* * *}$ & $1.74 \mathrm{~ns}$ & $0.99 \mathrm{~ns}$ & $0.52 \mathrm{~ns}$ & $3.74^{* * *}$ & $1.41 \mathrm{~ns}$ & $5.87^{* * *}$ \\
Submergence & 28 & $1.01 \mathrm{~ns}$ & $4.08^{* * *}$ & 1.16 & $0.99 \mathrm{~ns}$ & $0.82 \mathrm{~ns}$ & $1.89^{*}$ & $1.19 \mathrm{~ns}$ & $1.13 \mathrm{~ns}$ \\
\hline
\end{tabular}

Legend: ${ }^{\star}$ Significant at the threshold of $5 \%$ and ${ }^{* *}$ Significant at the threshold of $1 \%$ o. H13JAR $=$ height to 13 days after transplanting (cm); H45JA $=$ height to 45 days after transplanting $(\mathrm{cm})$; T13JAR = number of tillers at 13 days after transplanting; T45JAR = number of tillers at 45 days after transplanting; NE30JAR = number of internodes at 30 days after transplanting; NE45JAR = number of internodes at 45 days after transplanting; DE30JAR = length of internodes at 30 days after transplanting $(\mathrm{cm})$; DE45JAR = length of internodes at 45 days after transplanting $(\mathrm{cm})$.

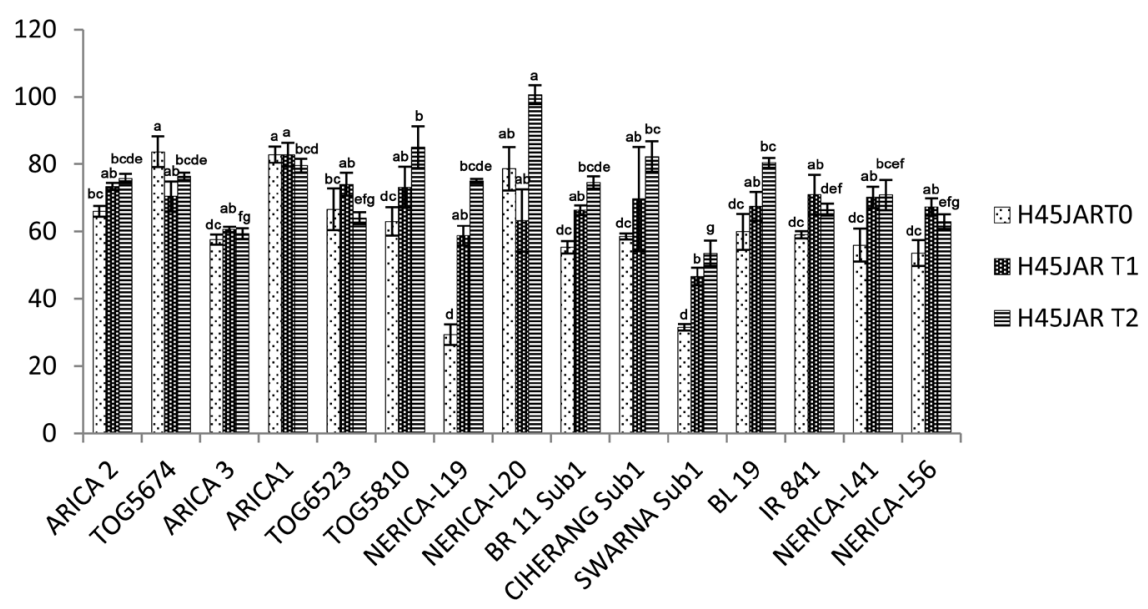

Figure 3. Height of the varieties in T0, T1 and T2. Varieties followed by the same letter: not significant; varieties followed different letter: significant.

\section{$\checkmark$ Partial submergence}

By comparing the height of the plants of varieties in partial submersion, it is noticed that the highest height is observed in the ARICA1 variety with an average of $82.83 \mathrm{~cm}$ and the smaller height is taken by the variety SwarnaSub1 (46.62 $\mathrm{cm})$. TOG6523, ARICA2, TOG5810 varieties also have heights in partial submersion (respectively $73.41 \mathrm{~cm} ; 74.00$ and $73.16 \mathrm{~cm}$ ). Means followed by the same letter are not significantly different.

\section{Total submergence}

Analysis of Figure 3 shows NERICAL-20 $(1.66 \mathrm{~m})$ is the variety that has size highest in total submersion. Then come, TOG5810, CIHERANGSub1 and BL19 varieties whose heights are respectively $85.05 \mathrm{~cm}, 82.25 \mathrm{~cm}$ and $80.41 \mathrm{~cm}$. It noted that there is a significant difference between NERICAL-20 and all the other varieties in terms of height for total submersion. In addition, is TOG 5810 significantly different from CIHERANGSub1 and the BL19 in total submersion considering the height criterion.

\subsection{Comparison of the Number of Internodes of Varieties to 45 Days}

\section{$\checkmark$ Without submergence}


In submersion zero, there is no significant difference between the varieties based on the number of internodes in 45 days (Figure 4). However, the highest average number of internodes is 5.25 and observed in the variety TOG 5810 (Figure 4).

\section{$\checkmark$ Partial submergence}

The variety with the highest number of internodes in 45 days is the 5810 TOG with an average of 5.25. This average allows noting a significant difference from all the other varieties in partial submersion (Figure 4). Then come, the varieties BL19 and NERICA-L20 with respectively as average 4.83 and 4.75 (Figure 4). Means followed by the same letter are not significantly different.

\section{$\checkmark$ Total submergence}

In total submersion, ARICA1 and ARICA2 have the highest averages in terms of number of internodes in 45 days (4.83 and 4.33) according to Figure 4. Means followed by the same letter are not significantly different.

\subsection{Significance of Yield Variables}

The variables used for the comparison of variables of yield will note firstly a significant difference between the types of submergence and on the other hand, a significant difference between the varieties. Thus, the analysis of variance (Table 2) shows that the factor type of submergence has an influence very highly significant ( $P \leq 0.0001$ on the length of grain and the ramifications of the secondary while she has a highly significant $(P \leq 0.001)$ effect on the average number of full grain per panicle. Other parameters such as width, thickness, the primary branches, and the weight of 1000 grains allow noted no significant differences between the types of submergence (Table 3 ). At the level of the variety factor, it should be noted that the variety has an influence very highly significant ( $P \leq$ 0.0001) on all parameters measured (Table 3).

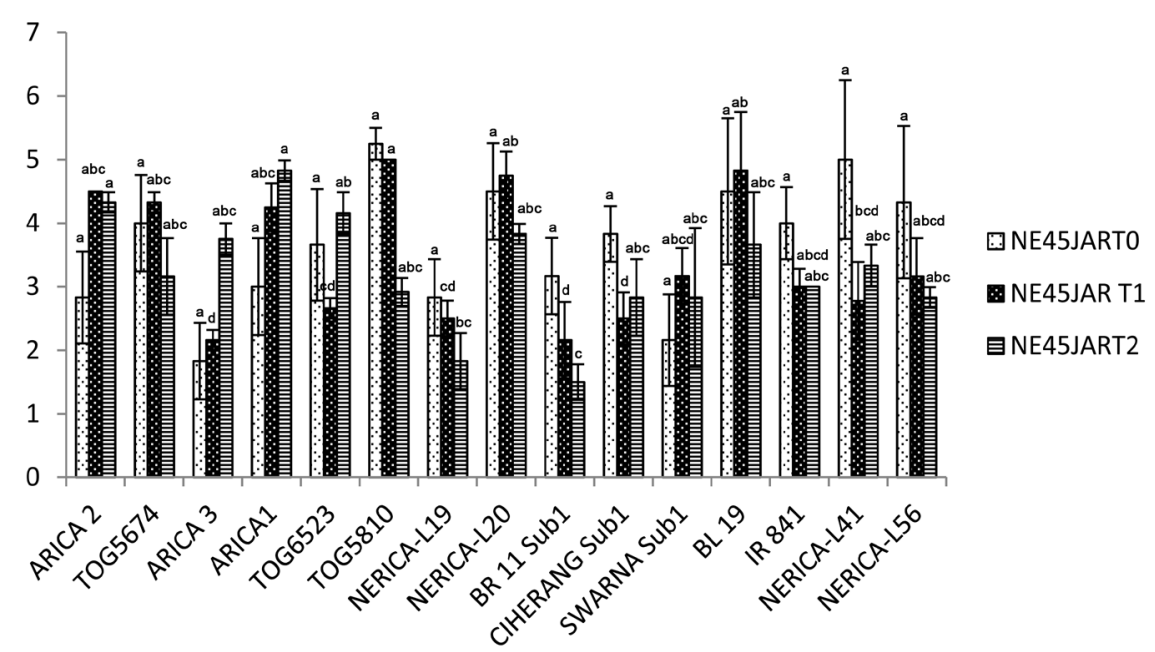

Figure 4. Number of internodes of varieties in partial, total and without submergence. Varieties followed by the same letter: not significant; varieties followed different letter: significant. 
Table 3. Significance of agro-morphological variables of yield.

\begin{tabular}{ccccccccccc}
\hline \multirow{2}{*}{ SSV } & DDL & \multicolumn{7}{c}{ Values of F and probabilities } \\
\cline { 3 - 10 } & & Lg & La & Ep & LgPa & Ram1 & Ram2 & Gvid & Gpln & P1000G \\
\hline Submergence & 2 & $23.84^{* * *}$ & $0.12 \mathrm{~ns}$ & $0.57 \mathrm{~ns}$ & $0.18 \mathrm{~ns}$ & $0.77 \mathrm{~ns}$ & $49.38^{* * *}$ & - & $9.10^{* *}$ & $1.04 \mathrm{~ns}$ \\
Variety & 14 & $128.68^{* * *}$ & $38.94^{* * *}$ & $14.33^{* * *}$ & $184.86^{* * *}$ & $102.22^{* * *}$ & $317.77^{* * *}$ & $440.49^{* * *}$ & $96.66^{* * *}$ & $579.48^{* * *}$ \\
Submergence $\times$ variety & 28 & $15.34^{* * *}$ & $0.14 \mathrm{~ns}$ & $0.63 \mathrm{~ns}$ & $1.72^{*}$ & $3.10^{* * *}$ & $36.14^{* * *}$ & $138.77^{* * *}$ & $9.71^{* * *}$ & $3.02^{* * *}$ \\
\hline
\end{tabular}

Legend: $\mathbf{L g}=$ length of grain $(\mathrm{mm}) \mathrm{La}=$ width of the grain $(\mathrm{mm}) \mathrm{Ep}=$ thickness of grain $(\mathrm{mm}) \mathbf{L g P a}=$ length of the panicle $(\mathrm{cm})$ Ram $1=$ number of primary branches Ram2 = number of secondary branches Gvid = average number of empty grains per panicle Gpln = average number of full grains per panicle P1000G = weight of 1000 grains (g). ${ }^{*}$ Significant at the threshold of $5 \%$ and ${ }^{* *}$ Significant at the threshold of $1 \%$. ${ }^{*}$ Significant at the threshold of $5 \%$ and ${ }^{* * *}$ Significant at the threshold of $1 \%$.

Interaction submergence and varieties has an influence very highly significant $(P \leq 0.0001)$ along the length of the grain, the length of the panicles, the number of primary and secondary branches, the number of empty grain full grain and finally on the weight of 1000 grains. However, it is noted that the interaction variety and submergence has no significant influence on the width and thickness of grain (Table 3 ).

\subsection{Comparison of the Weight of Thousand Grains of Rice Varieties \\ Without submergence}

In normal condition without submergence, the variety that has the highest weight of thousand grains is the IR841 variety with an average of $31.80 \mathrm{~g}$. Follow, varieties BL19, NERICAL19 and ARICA3 with a average respective $30.53 \mathrm{~g}$; $30.20 \mathrm{~g}$ and $30.10 \mathrm{~g}$ (Figure 5). Means followed by the same letter are not significantly different.

\section{$\checkmark$ Partial submergence}

The weight of the highest measured of thousand grains, in partial submersion is the variety BL19 (31.80 g) followed by the varieties TOG5810 and NERICAL19 with the respective average $30.30 \mathrm{~g}$ and $30.10 \mathrm{~g}$ (Figure 5). In addition, averages followed the same letter are not significantly different.

\section{$\checkmark$ Total submergence}

In complete submersion, two varieties have a considerable weight of thousand grains compared to the other varieties. It is the BL19 and the IR841 with the respective average $30.80 \mathrm{~g}$ and $30.79 \mathrm{~g}$ (Figure 5). Means followed by the same letter are not significantly different.

\subsection{Comparison of the Average Number of Empty Grains per Panicle}

\section{$\checkmark$ Without submergence}

CIHERANG Sub1 has less empty grains per panicle (4.8 average); it's significantly different from the others (Figure 6). The TOG 5810 variety has less empty grain over other varieties (7.70 g on average). This variety is significantly different from the others in terms of the average number of empty grains per panicle. 


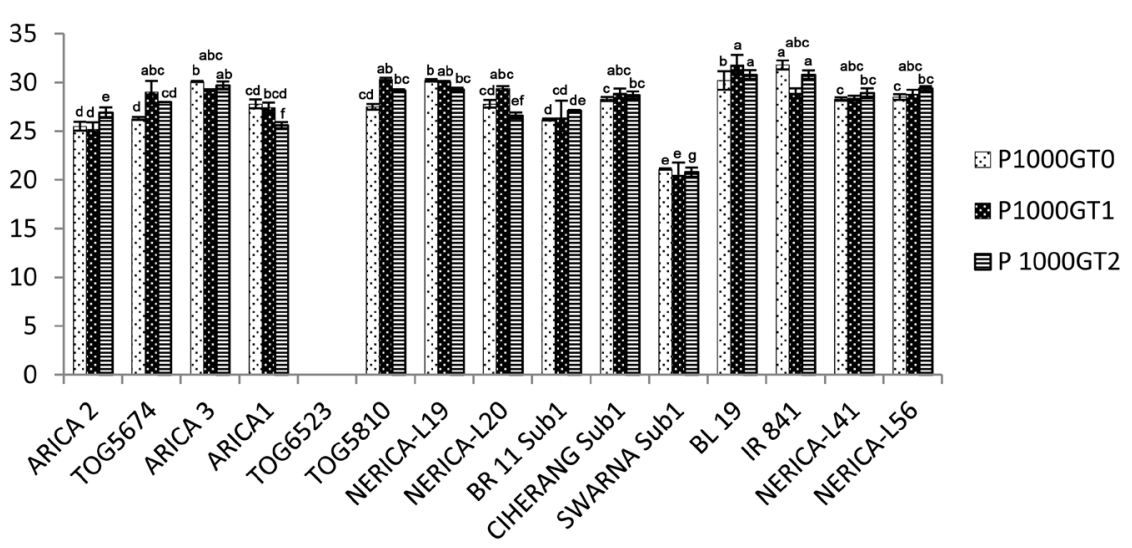

Figure 5. Weight of thousand grains of rice varieties in partial, total and without submergence. Varieties followed by the same letter: not significant; varieties followed different letter: significant.

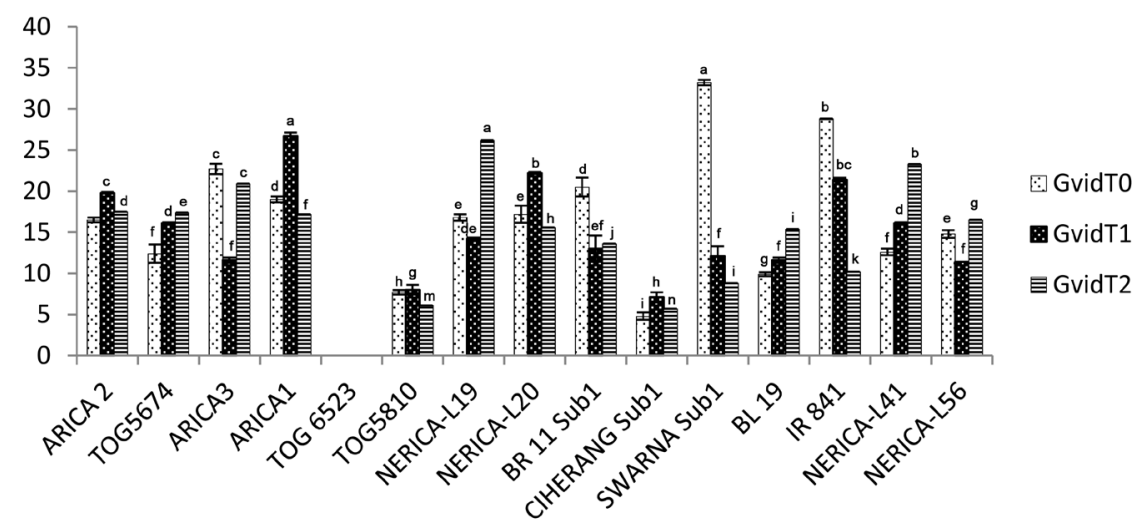

Figure 6. Average number of empty grains per panicle in T0, T1 and T2. Varieties followed by the same letter: not significant; varieties followed different letter: significant.

It is worth noting that in normal condition, the Swarna-Sub1 and the IR841 variety have more empty seeds than other varieties (Figure 6).

\section{$\checkmark$ Partial submergence}

In partial submergence, the varieties CIHERANG Sub1 and TOG5810 produce less empty grains per panicle compared to other varieties $(7.10 \mathrm{~g}$ and $9.00 \mathrm{~g}$ respectively). These varieties are significantly different one from each other and different from the other varieties (Figure 6). On the other hand, the largest average number of empty grains per panicle is observed in the varieties ARICA1 and IR841 in partial submergence.

\section{$\checkmark$ Total submergence}

It is observed that the varieties CIHERANG Sub1 and TOG5810 still have an average number of empty grain less than other varieties (respectively 5.7 and 6.10). At the same time, the NERICAL-19, NERICAL-41 varieties have a number of empty grains higher than other varieties. It noted that there is significant difference between CIHERANGSub1 and TOG5810 based on the average number of empty grains per panicle in total submersion (Figure 6). 


\subsection{Comparison of the Number of Primary Branches in the Three Types of Submergence}

\section{$\checkmark$ Without submergence}

In condition of not submergence, the TOG 5674 has the largest number of primary branches (14.01) followed by the Swarna-Sub1 (13.40) and the IR841 (12.80) (Figure 7). Means followed by the same letter are not significantly different.

\section{$\checkmark$ Partial submergence}

The numbers of the higher primary branches are noticed in the Swarna-Sub1 (13.63) followed by the TOG 5810 (11.83) and the ARICA1 (12.01) (Figure 7). There are difference between Swarna-Sub1 and two other varieties so that there is no significant difference between TOG5810 and ARICA1 in terms of the number of primary branches for partial submergence (Figure 7).

\section{$\checkmark$ Total submergence}

In complete submergence, varieties with the highest number of branches are in the first place, the SwarnaSub1 (13.60), secondly the TOG 5674 (13.40) and finally the BL19 (12.5) and the NERICAL-20 (12.06) (Figure 7). There was no significant difference between the Swarna-Sub1 and the TOG5674 but they are significantly different from the BL19, NERICAL-20. On the other hand, the BL19 is significantly different from the NERICAL-20 in terms of numbers of primary branches regarding the total submergence.

\subsection{Comparison of the Number of Secondary Branches According to the Three Types of Submergence \\ $\checkmark$ Without submergence}

It is noticed as many secondary ramifications with Swarna-sub1, NERICAL-20, BL19, and BR11Sub1 varieties with respectively an average of $31.75,33.83$ and 31.39 (Figure 8).

\section{$\checkmark$ Partial submergence}

BR11-Sub1, SwarnaSub1, NERICAL-56 and NERICAL-41 are the varieties

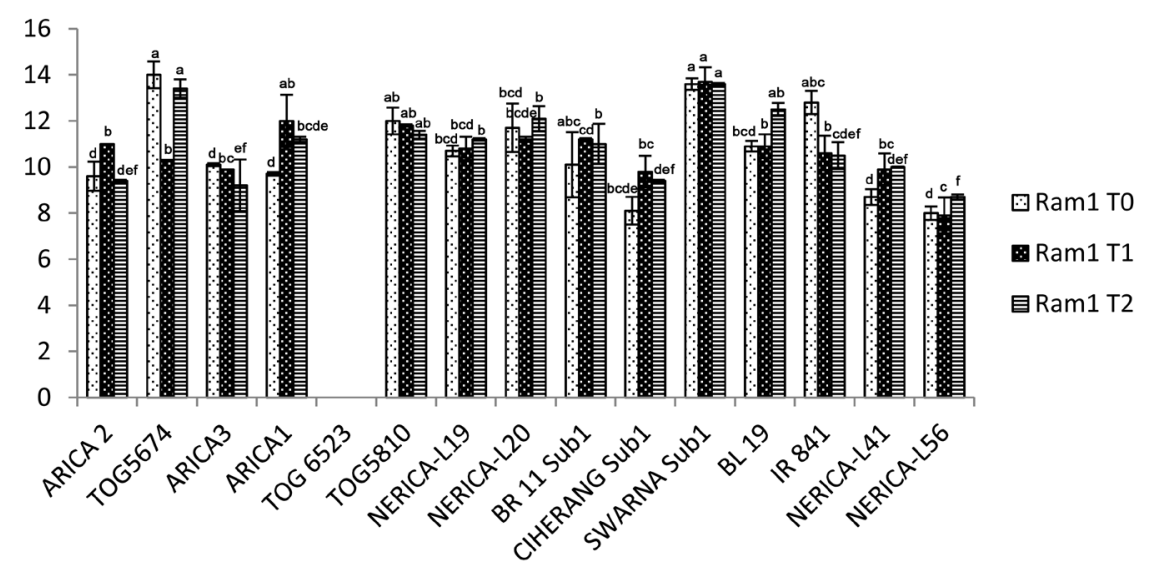

Figure 7. Number of primary branches varieties in $\mathrm{T} 0, \mathrm{~T} 1$ and $\mathrm{T} 2$. Varieties followed by the same letter: not significant; varieties followed different letter: significant. 


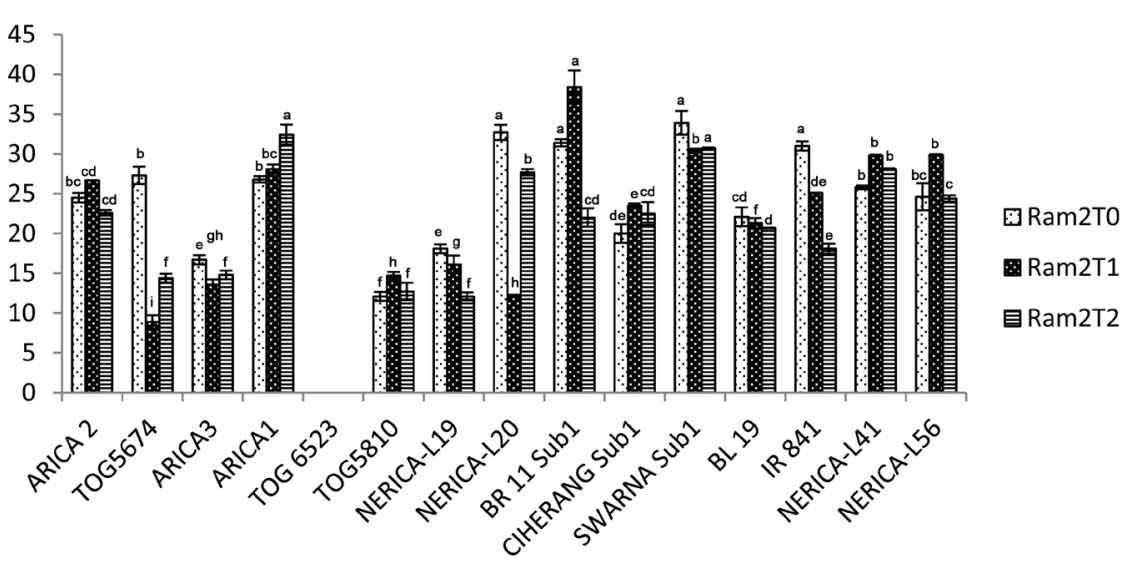

Figure 8. Secondary ramifications of different varieties in T0, T1 and T2. Varieties followed by the same letter: not significant; varieties followed different letter: significant.

that have the largest numbers of secondary for partial submersion with respective average $38.40,30.4629 .78$ and ramifications 29.80 (Figure 8). There is a significant difference between BR11Sub1 and SwarnaSub1 in terms of secondary ramifications (Figure 8).

\section{$\checkmark$ Total submergence}

ARICA1 is the first variety with the highest number of secondary ramifications (32.53). Then follow, Swarna Sub1 (30.70), NERICAL-41 varieties (28.10) and NERICAL-20 (27.70) (Figure 8). Means followed by the same letter are not significantly different.

\section{Discussion}

The results of the analysis of variance ANOVA showed that the type of submergence and the type of variety influenced significantly the height at 45 days after transplanting.

Indeed, it is noticed that the lower heights in total and partial submergence are observed in the Swarna-Sub1. In fact, this variety is obtained in 2002 [16] from the intersection of FR13A and the Swarna. The FR13A variety is the result of the improved IR49830-7 lines (Sub1) and contains a submergence tolerance gene called Sub1 [16]. The work of Sarkar [17] showed that SwarnaSub1 survived in a complete submergence of 12 days so that, in the study current plants are submerged for 60 days and the data are taken and analysed to 35 days after submergence. The long-term partial submergence could explain the weakest recorded heights at the Swarna sub1 and the sensitivity of this variety. According to Colmer and Voesenek [18], a crucial point, which should be taken into account in the study of the submergence, is the duration of submergence. Indeed, the factor duration of submergence has been recognized as a major factor in the survival process of the plant as result of the lack of oxygen [19]. In addition, he showed that a species of the same age and a similar size able to survive for a short period of submergence could perish if it is exposed to a long period of submergence [20]. That is what would explain the lowest observed in the Swar- 
naSub1 heights. The mechanism underlying the growth reduction in size or low height observed in the SwarnaSub1 would result from the effect of the environment on the plant since according to Setter [21], submergence caused a low oxygen supply rate; What prevents or limits the respiration of the plant and creates a deficit in energy within the plant. The growth of the plant becomes so reduced or limited; which can lead to the death of the plant [21].

On the other hand, the greatest heights in partial and total submergence noticed at the NERICAL-20, the TOG5810 and the ARICA1. The TOG 5810 is $O$. glaberrima and NERICAL-20 an interspecific variety of $O$. glaberrima and $O$. sativa. According to Futakuchii [22], TOG5810 and TOG 6283 lines are lines identified by IITA for their tolerance to submergence and according to their studies, there was no significant difference between these lines in terms of tolerance to submergence based on the assessment of chlorophyll, oxygen content and the height in submergence condition. The work of these authors have identified significant differences between the lines of $O$. glaberrima (TOG 5810, TOG 6283) and the lines of $O$. sativa (IR36, Norin30) studied their mechanism of tolerance to submergence. Also, conducted experiments, allowed them to say that in General, $O$. glaberrima lines are usually more tolerant to submergence than the lines of O. sativa. Thus, lines of O. glaberrima (TOG5810 and TOG6283) showed a great capacity for siding full submergence through the stem elongation or the rapid growth in height compared to the varieties of O. sativa (IR36, Norin30) [22]. The results of the present work confirm those reported by Futakuchii [22]. In addition, it is important to remember that $O$. glaberrima identified as variety tolerant to many biotic stress and abiotic [23].

NERICAL-20 has a large size $(1.66 \mathrm{~m})$ in total submergence. Indeed, this variety is interspecific and is the result of a cross between TOG5681 and the IR64. As TOG 5681 is a glaberrima and IR64, sativa, to F2, the proportions obtained after crossing would be $3 / 4$ and $1 / 4$. NERICAL-20 would have inherited tolerance and characters of large size in the species of $O$. glaberrima (TOG5681). This is what justifies this larger size and the good performance of tolerance to total submergence observed during this study.

\section{Conclusion}

At the end of this study, it noted that 15 studied varieties have reacted differently to submergence. Growth parameters, such as height and number of internodes

in 45 days and performance metrics measured as the length of the grain, the length of the panicles, the number of primary and secondary branches, the average number of empty grain and full grains per panicle as well as the weight of 1000 grains helped to assess the response of different varieties of rice under submerged condition in order to distinguish tolerant varieties of the most sensitive.

\section{References}

[1] Bailey-Serres, J. and Voesenek, L.A.C.J. (2008) Flooding Stress: Acclimations and 
Genetic Diversity, Annual Review of Plant Biology.

[2] Bailey-Serres, J., Fukao, T., Ronald, P., Ismail, A., Heuer, S. and Mackill, D. (2010) Submergence Tolerant Rice: SUB1's Journey from Landraceto Modern Cultivar, Published with Open Access at Springerlink.com. 141.

[3] Balasubramanian, V., Sié, M., Hijmans, R.J. and Otsuka, K. (2007) Increasing Rice Production in Sub-Saharan Africa: Challenges and Opportunities. Advances in Agronomy, 55-133. https://doi.org/10.1016/S0065-2113(06)94002-4

[4] Catling, D. (1992) Rice in Deep Water. International Rice Research Institute, Manila, 542 p. https://doi.org/10.1007/978-1-349-12309-4

[5] Colmer, T.D. (2003) Long-Distance Transport of Gases in Plants: A Perspective on Internal Aeration and Radial Oxygen Loss from Roots. Plant, Cell \& Environment, 17-36. https://doi.org/10.1046/j.1365-3040.2003.00846.x

[6] Colmer, T.D. and Voesenek, L.A.C.J. (2009) Flooding Tolerance: Suites of Plant Traits in Variable Environments. Functional Plant Biology, 665-681. https://doi.org/10.1071/FP09144

[7] Emes, M.J., Wilkins, C.P., Smith, P.A., Kupkanchanakul, K., Hawker, K. and Charlton, W.A. (1988) Starch Utilization by Deepwater Rice during Submergence. Proceedings of the 1987 International Deepwater Rice Workshop, International Rice Research Institute, Manila, 319-326.

[8] World Bank and United Nations (2011) Needs Assessment Report Post Disaster. 84 p.

[9] Futakuchi, K., Jones, M.P. and Ishii, R. (2001) Physiological and Morphological Mechanisms of Submergence Resistance in African Rice (Oryza glaberrima Steud.). Japanese Society for Tropical Agriculture, 8-14.

[10] Ghesquiere, A., Sequier, J., Second, G. and Lorieux, M. (1997) First Steps towards a Rational Use of African Rice, Oryza glaberrima, in Rice Breeding through Acontig Line Concept. Ibid. 31-39.

[11] Haefele, S.M., Ismail, A.M., Johnson, D.E., Vera Cruz, C. and Samson, B. (2010) Crop and Natural Resource Management for Climate-Ready Rice in Unfavorable Environments: Coping with Adverse Conditions and Creating Opportunities. Presentation at the CURE Workshop on Climate Change, Siem Reap, Cambodia, 4 May 2010.

[12] Ismail, A.M. and Mackill, D.J. (2013) Response to Flooding: Submergence Tolerance in Rice. In: Jackson, M., Ford-Lloyd, B. and Parry, M., Eds., Plant Genetic Resources and Climate Change, 251-269.

[13] Jackson, M.B., Kimiharu, I. and Osamu, I. (2009) Evolution and Mechanisms of Plant Tolerance to Flooding Stress. Annals of Botany, 103, 137-142.

https://doi.org/10.1093/aob/mcn242

[14] Mallik, S., Kundu, C., Banerji, C., Nayak, D.K, Chatterji, S.D. and Nanda, P.K. (1995) Rice Germplasm Evaluation and Improvement for Stagnant Flooding. In: Ingram, K.T., Ed., Rainfed Lowland Rice: Agricultural Research for High Risk Environments, International Rice Research Institute, Manila, 97-109.

[15] Mackill, D.J., Coffman, W.R. and Garrity, D.P. (1996) Rainfed Lowland Rice Improvement. International Rice Research Institute, Manila, Philippines, $242 \mathrm{p}$.

[16] Palada, M. and Vergara, B.S. (1971) Environmental Effect on the Resistance of Rice Seedlings to Complete Submergence. Crop Science, 12, 209-212. https://doi.org/10.2135/cropsci1972.0011183X001200020018x

[17] Setter, T.L., Ingram, K.T. and Tuong, T.P. (1995) Environmental Characterization 
Requirements for Strategic Research in Rice Grown under Adverse Conditions of Drought, Flooding or Salinity. In: Ingram, K.T., Ed., Rainfed Lowland Rice-Agricultural Research for High Risk Environments, International Rice Research Institute, Manila.

[18] Sossou-agbo, A.L. (2013) Socio-Economic Impacts of Floods of 2010 in the Delta of the Ouéme in Benin, 26th Symposium of the International Association of Climatology. Pacte Laboratory-Territories, UJF-Grenoble. sossoulazare@yahoo.f

[19] Voesenek, L.A.C.J, Colmer, T.D., Pierik, R., Millenaa, F.F. and Peeters, A.J.M. (2006) How Plants Cope with Complete Submergence. New Phytologist, 170, 213-226. https://doi.org/10.1111/j.1469-8137.2006.01692.x

[20] Colmer, T.D., Cox, M.C.H. and Voesenek, L.A.C.J. (2006) Root Aeration in Rice (Oryza sativa): Evaluation of Oxygen, Carbon Dioxide, and Ethylene as Possible Regulators of Root Acclimatizations. New Phytologist, 170, 767-778. https://doi.org/10.1111/j.1469-8137.2006.01725.x

[21] Catling, D. (1992) Rice in Deep Water. Macmillan Press, London. https://doi.org/10.1007/978-1-349-12309-4

[22] Armstrong, W. and Drew, M.C. (2002) Root Growth and Metabolism under Oxygen Deficiency. In: Waisel, Y., et al., Plant Roots. The Hidden Half, 3rd Edition, New York, Basel, 729-761.

[23] Cho, H.T. and Kende, H. (1997) Expansins in Deepwater Rice Internodes. Plant Physiology, 113, 1137-1143. https://doi.org/10.1104/pp.113.4.1137 